\title{
MANEJ O CLÍNICO DA GESTANTE COM HIV POSITIVO NAS MATERNIDADES DE REFERÊNCIA DA REGIÃO DO CARIRIa
}

\author{
Clinical management of the hiv positive pregnant women in reference maternities \\ from the region of Cariri \\ Manej o clínico de la embarazada hiv positivo en las maternidades de referencia de la \\ región de Cariri
}

Camilla Thania Dias de Lima ${ }^{1} \quad$ Dayannne Rakelly de Oliveira ${ }^{2} \quad$ Edilma Gomes Rocha ${ }^{3} \quad$ Maria Lúcia Duarte Pereira ${ }^{4}$

\section{RESUMO}

Esta pesquisa objetivou identificar como ocorre o manejo clínico e medicamentoso da gestante com HIV nas maternidades de referência da região do Cariri. Estudo descritivo, retrospectivo, com dados de 22 prontuários e 21 fichas de notificação entre agosto de 2003 e setembro de 2007, analisados por estatística descritiva. Todas as gestantes realizaram 4 a 6 consultas de prénatal. A maioria recebeu profilaxia com AZT; foram realizados 16 testes rápidos para o HIV. 0 parto cesáreo foi o mais utilizado; 17 receberam AZT intraparto e esquema completo; 9 iniciaram o AZT intravenoso antes de três horas de internação. No puerpério, sete realizaram inibição mecânica da lactação; duas, inibições hormonais; e oito, os dois métodos. Todos recémnascidos receberam AZT oral e fórmula infantil. As maternidades investigadas seguem as orientações do MS quanto: uso de teste rápido, escolha do tipo de parto, profilaxia com AZT intravenoso, inibição da lactação e cuidados imediatos aos recém-nascidos.

Palavras-chave: Síndrome da Imunodeficiência Adquirida. Gestantes. Transmissão Vertical de Doença.

\begin{abstract}
This research is aimed to identify how the medical and clinical management of pregnant women with HIV in hospitals in the reference region of Cariri occurs. Descriptive, retrospective study, with data from 22 medical and 21 from notification sheets between August 2003 and September 2007, analyzed by descriptive statistics. All women underwent 4 to 6 prebirthing consultations. Most had received prophylaxis with AZT; conducted 16 rapid tests for HIV. The cesarean section was the most used, 17 received intrapartum AZT and complete schedule, 9 started AZT intravenously before three hours in hospitalization. In the puerperium, seven underwent mechanical inhibition of lactation, two losses and eight both hormonal methods. All newborns have received oral AZT and infant formula. The investigated maternity hospitals following the guidelines on MS: use of rapid test, select the type of delivery, prophylaxis with intravenous AZT, inhibition of lactation and immediate care to newborns.
\end{abstract}

Keywords: Acquired Immunodeficiency Syndrome. Pregnancy. Disease Vertical transmisión.

\section{Resumen}

Esta investigación objetivó identificar como ocurre el manejo clínico y medicamentoso de las mujeres embarazadas con VIH en las maternidades de referencia de la región de Cariri. Estudio descriptivo, retrospectivo, con datos de 22 prontuarios y 21 fichas de notificación de agosto de 2003 hasta septiembre de 2007, analizados por estadística descriptiva. Todas las mujeres embarazadas realizaron de 4 a 6 consultas de prenatal. La mayoría recibió profilaxis con AZT; realizados 16 exámenes rápidos para el VIH. El parto [cesáreo] fue el más utilizado; 17 recibieron AZT intraparto y esquema completo; 9 iniciaron el AZT intravenoso antes de tres horas de internación. En el puerperio, siete realizaron inhibición mecánica de la lactación, dos inhibiciones hormonales y ocho, los dos métodos. Todos los recién nacidos recibieron AZT oral y fórmula infantil. Las maternidades investigadas siguen las orientaciones del MS cuanto: uso de examen rápido, elección en el tipo de parto, profilaxis con AZT intravenoso, inhibición de la lactación y cuidados inmediatos a los recién nacidos.

Palabras Claves: Síndrome de la Inmunodeficiencia Adquirida. Mujeres Embarazadas. Trasmisión vertical de enfermedad.

'Monografia apresentada para conclusão de curso. (Bacharelado em Enfermagem), 2008.Cariri-CE-Brasil. E-mail: camillathania@hotmail.com, ${ }^{2}$ Mestranda em Bioprospecção Molecular pela URCA. Especialista em Obstetrícia, docente da Universidade Regional do Cariri (URCA).Cariri-CE-Brasil. E-mail: dayanne_rakelly@yahoo.com.br, ${ }^{3}$ Doutoranda em Enfermagem da Universidade de São Paulo (USP), docente da Universidade Regional do Cariri (URCA).CaririCE- Brasil. E-mail: edilma.rocha@yahoo.com.br, ,Doutora em Enfermagem, docente da Universidade Estadual do Ceará (UECE), Fortaleza-CE. Brasil. E-mail: mlduarte@fortalnet.com.br 


\section{INTRODUÇÃO}

A síndrome da imunodeficiência adquirida (AIDS) é a fase mais avançada da infecção pelo Vírus da Imunodeficiência Humana (HIV), doença emergente, transmissível e de comportamento pandêmico considerada um dos maiores problemas de saúde pública. ${ }^{\dagger}$ As tendências de transmissão deixam de ser restritas aos "grupos de riscos" e passam a ser presentes no fenômeno de pauperização, feminização, interiorização e juvenilização na população. ${ }^{2}$

Em termos globais, têm-se 17,3 milhões de mulheres com 15 anos ou mais, vivendo com HIV, ou seja, cerca de $50 \%$ do total da população infectada. No Brasil, a razão de sexo está diminuindo e tornando-se equivalente, passando de 15,1 homens/mulheres (1986) para 1,5 homens/mulher (2005); identifica-se, então, o crescimento da infecção nas mulheres, ${ }^{3}$ sendo este o reflexo do compor tamento sóciosexual, aliado às questões de vulnerabilidade biológica e de gênero, bem como à crença generalizada que as mulheres estariam imunes e/ou menos expostas.

A concentração de mulheres infectadas na faixa etária de 25 a 34 anos traz como consequência o aumento da transmissão vertical, pois essas mulheres encontram-se em plena fase reprodutiva. ${ }^{4} \mathrm{~A}$ transmissão vertical do HIV pode ocorrer durante a "gestação (65\%), no periparto (35\%) e amamentação entre $7 \%$ e 22\%". ${ }^{5}$ Tal fato, levou o Ministério da Saúde a determinar este agravo como de notificação compulsória, tornando-o obrigatório e regulamentado pela Portaria no 993/GM, de 04/09/2000. ${ }^{6}$

No período entre 1996 e 2005, ocorreu redução de transmissão vertical de 51,5. Isso foi atribuído à melhoria do acompanhamento às gestantes pelos serviços de saúde, tanto nas Unidades Básicas de Saúde (UBS) quanto nas maternidades durante o parto. ${ }^{7}$

Diante do quadro da transmissão vertical do vírus, um estudo multicêntrico realizado nos Estados Unidos e na França, Protocolo 076 do Aids Clinical Trial Group (ACTG 076), mostrou que a administração da Zidovudina (AZT) na gestação, durante o parto e para o recém-nascido, reduz a taxa de transmissão materno-infantil para 8,3\%. Contudo, a literatura mostra que, com a aplicação de todas as intervenções preventivas, essa redução pode variar de $1 \%$ a $2 \% .^{5}$

Segundo o Estudo Sentinela Parturiente de 2004, a incidência de HIV em gestantes tem-se mantido menor que $1 \%$ em todo o país, mas mostra variações entre as regiões, e a prevalência do Nordeste chegou a $0,225 \%$. Outros dados revelados nessa pesquisa mostram que a cobertura de sorologia para HIV na gestação foi estimada em $63 \%$, sendo a do Nordeste $31 \%$, evidenciando, mais uma vez, desigualdades regionais. ${ }^{7}$

Assim, o Ministério da Saúde (MS) destaca que legislação, tecnologia e insumos para a redução da transmissão vertical do HIV já existem e são disponibilizados pelas instâncias federal, estadual e municipal. No entanto, os dados epidemiológicos não são satisfatórios e mostram a necessidade de medidas mais eficazes para a redução desse agravo. ${ }^{5}$ Como estratégia, foi lançada pelo MS, em 2003, o Projeto Nascer, que tem como intuito principal o acolhimento, o aconselhamento e testagem rápida para HIV nas parturientes que não foram avaliadas no pré-natal. Estas constituem uma das estratégias de ampliar o acesso das gestantes ao diagnóstico da infecção. ${ }^{4}$

A motivação pelo estudo decorreu da observação de que, na prática, a realização do teste sorológico gratuito como exame de rotina pré-natal nem sempre está disponível, o que é somado a demora dos resultados. Acredita-se, portanto, na sua relevância pela possibilidade de identificar 0 atendimento às gestantes com HIV positivo nas maternidades.

Dessa forma, seguindo-se como parâmetro as atuais recomendações do MS para a condução das gestantes soropositivas para o HIV, investigou-se o seguinte problema de pesquisa: Qual o manejo clínico direcionado às gestantes com HIV positivo atendidas pelas maternidades de referência da região do Cariri? Mediante esse levantamento, correlacionaram-se as informações encontradas com as existentes na literatura, principalmente com as do MS, em especial o Projeto Nascer nas Maternidades.

0 presente estudo teve os seguintes objetivos: Identificar o manejo clínico-medicamentoso e epidemiológico da gestante com HIV positivo; verificar as ações para prevenção da transmissão vertical do HIV após a implantação do Projeto Nascer nas Maternidades e correlacionar as ações implementadas nas Maternidades com as recomendaç̃̃es atuais do Ministério da Saúde.

\section{METODOLOGIA}

Trata-se de um estudo de caráter descritivo, retrospectivo documental, com abordagem quantitativa. 0 cenário desse estudo compreendeu as maternidades de referência da Região do Cariri, ou seja, a maternidade do Crato (entidade filantrópica), de Juazeiro do Norte (instituição municipal.) e na cidade de Barbalha (instituição filantrópica).

Foram fontes de coletas de dados: prontuários clínicos e fichas de notificação compulsória, sendo 22 prontuários selecionados de gestantes com HIV, atendidas nas maternidades referidas, e ainda 21 fichas de notificação compulsória de gestantes com HIV positivo/ crianças expostas, pertencentes ao arquivo do Núcleo Hospitalar de Epidemiologia - NUHEP. Esta fonte foi utilizada pelo fato de que as informações do Sistema de Informação de Agravos de Notificação - SINAN 
encontravam-se incompletas, com apenas sete registros observados.

A investigação ocorreu no período de agosto de 2003 a setembro de 2007, em virtude de abranger desde a implantação do Projeto Nascer nas Maternidades até a elaboração do estudo em questão.

Os critérios de inclusão foram: ser gestante, estar vivendo com HIV, ter sido atendida em uma das maternidades de referência no período de tempo mencionado; possuir prontuário arquivado no Serviço de Arquivo Médico e Estatística (SAME) das instituições hospitalares; ter sido notificada no SINAN. Foram critérios de exclusão: ser gestante com HIV positivo atendida em período diferente do escolhido para o estudo; não ser registrada em caderno de protocolo das maternidades; não ser notificada no SINAN e não ter informações em caderno de protocolo das maternidades; gestante com HIV que sem prontuário arquivado no SAME das instituições hospitalares.

A coleta de dados ocorreu entre dezembro de 2007 e janeiro de 2008, após emissão do parecer favorável do Comitê de Ética da Faculdade de Medicina de Juazeiro do Norte - FMJ (protocolo n 65/07 data 03/12/2007) e autorização da pesquisa pelas instituições hospitalares e secretarias de saúde supracitadas.

As informações foram provenientes do formulário da ficha de notificação compulsória, atendendo às seguintes variáveis: sociodemográficas (idade, nível de escolaridade, ocupação e estado civil), clínico-obstétricas e terapêuticas, enfatizando dados sobre o pré-natal, diagnóstico sorológico e conduta no serviço obstétrico.

Após a coleta, os dados foram organizados no programa informático Microsoft Excel e submetidos à análise estatística, considerou-se a frequência absoluta e percentual. Os resultados foram apresentados em tabelas e quadros e discutidos com a literatura existente, analisando-os à luz das recomendações atuais do Ministério da Saúde.

\section{RESULTADOS}

\section{Caracterização dos sujeitos}

a) Características sociodemográficas

Apresentam-se na Tabela 1 as características sociodemográficas das 22 gestantes com HIV positivo, nas maternidades de referência da Região do Cariri. As gestantes estudadas eram adultas jovens, com faixa etária entre 17 e 35 anos, prevalecendo a faixa etária de 17 a 21 anos. Quanto à escolaridade, nove $(41 \%)$ tinham 4 a 7 anos de estudo. Verificou-se também que $50 \%$ delas eram trabalhadoras do lar, o restante exercia atividades de agricultora $(18,2 \%)$, estudante $(13,6 \%)$, doméstica $(9,1 \%)$ e vendedora $(9,1 \%)$. Considerando o estado civil, $14(63,6 \%)$ eram solteiras e oito $(36,4 \%)$ eram casadas.

\begin{tabular}{|c|c|c|c|}
\hline Variáveis & $\mathbf{F}$ & Fr & $\%$ \\
\hline Idade & & & \\
\hline $17-21$ & 10 & 0,454 & 45,4 \\
\hline $22-26$ & 6 & 0,273 & 27,3 \\
\hline $27-31$ & 4 & 0,182 & 18,2 \\
\hline 32 ou mais & 2 & 0,091 & 9,1 \\
\hline Nível de escola & & & \\
\hline Nenhum & 2 & 0,091 & 9,1 \\
\hline De 1 a 3 anos & 3 & 0,136 & 13,6 \\
\hline De 4 a 7 anos & 9 & 0,41 & 41 \\
\hline De 8 a 11 anos & 5 & 0,227 & 22,7 \\
\hline De 12 a mais & 3 & 0,136 & 13,6 \\
\hline Ocupação & & & \\
\hline Do Lar & 11 & 0,5 & 50 \\
\hline Agricultora & 4 & 0,182 & 18,2 \\
\hline Estudante & 3 & 0,136 & 13,6 \\
\hline Doméstica & 2 & 0,091 & 9,1 \\
\hline Vendedora & 2 & 0,091 & 9,1 \\
\hline Outras & & & \\
\hline Estado civil & & & \\
\hline Solteira & 14 & 0,636 & 63,6 \\
\hline Casada & 8 & 0,364 & 36,4 \\
\hline TOTAL & 22 & 1 & 100 \\
\hline
\end{tabular}

Fonte: Pesquisa direta em prontuários hospitalares.

\section{b) Características epidemiológicas}

A exposição da propedêutica perinatal das gestantes no estudo é visualizada na Tabela 2. 0 registro do pré-natal estava presente em todos os prontuários das gestantes, entretanto o número de consultas predominantes foi de quatro a seis (50\%), e oito $(36,4 \%)$ gestantes realizam sete a mais consultas.

Quanto ao momento de diagnóstico da mãe, onze casos (50\%) ocorreram durante o pré-natal, e quatro $(18,2 \%)$ mulheres já sabiam seu diagnóstico antes da gestação. As maternidades diagnosticaram cinco $(22,7 \%)$ dos casos durante o parto, e duas $(9,1 \%)$ só souberam que estavam infectadas pelo vírus HIV após o parto.

Verificou-se que dez $(45,5 \%)$ gestantes não fizeram profilaxia para HIV durante o pré-natal. Este fato esteve associado à não identificação precoce do status sorológico da gestante, sendo as justificativas encontradas nas fichas de notificação compulsória das gestantes com HIV positivo e crianças expostas, as seguintes: a longa espera em filas para marcar exames, a demora em recebê-los, a realização de poucas consultas pré-natais e a não solicitação do teste HIV pelos profissionais. 
A realização de teste rápido para o HIV nas maternidades aconteceu em 16 (72,2\%) dos casos, independentes de játerem feito a sorologia antes ou durante o pré-natal. Com essa estratégia, como consta na Tabela 2, foi possível detectar durante o parto cinco
(22,7\%) dos casos que desconheciam a sua soropositividade, além de uma paciente que, mesmo sabendo de sua condição sorológica, não mencionou o fato no momento do parto; e duas $(9,1 \%)$ só foram detectadas após o parto.

\begin{tabular}{|c|c|c|c|}
\hline \multicolumn{4}{|c|}{$\begin{array}{l}\text { TABELA 2: Distribuição das gestantes com HIV positivo segundo o no de consultas } \\
\text { no pré-natal, momento de diagnóstico da infecção pelo HIV da mãe, início do uso de } \\
\text { antirretroviral (ARV), medicações utilizadas e realização do teste rápido para HIV } \\
\text { nas maternidades de referências da Região do Cariri. Brasil. } 2003 \text { - } 2007 .\end{array}$} \\
\hline Variáveis & $\mathbf{F}$ & Fr & $\%$ \\
\hline \multicolumn{4}{|l|}{$\mathrm{N}^{0}$ de consultas no pré-natal } \\
\hline De 1 - 3 & 1 & 0,045 & 4,5 \\
\hline De $4-6$ & 11 & 0,5 & 50 \\
\hline De 7 e mais & 8 & 0,364 & 36,4 \\
\hline Ignorado & 2 & 0,091 & 9,1 \\
\hline \multicolumn{4}{|l|}{ Momento do diagnóstico } \\
\hline Antes do pré-natal & 4 & 0,182 & 18,2 \\
\hline Durante o pré-natal & 11 & 0,5 & 50 \\
\hline Durante o parto & 5 & 0,227 & 22,7 \\
\hline Após o parto & 2 & 0,091 & 9,1 \\
\hline \multicolumn{4}{|c|}{ Início do uso de antirretroviral } \\
\hline $2^{\circ}$ trimestre & 7 & 0,318 & 31,8 \\
\hline $3^{\circ}$ trimestre & 1 & 0,045 & 4,5 \\
\hline Sem registro de início & 4 & 0,182 & 18,2 \\
\hline Não usou & 10 & 0,455 & 45,5 \\
\hline \multicolumn{4}{|l|}{ Medicações utilizadas } \\
\hline AZT & 8 & 0,364 & 36,4 \\
\hline AZT + outro ARV & 2 & 0,091 & 9,1 \\
\hline Medicamento não informado & 2 & 0,091 & 9,1 \\
\hline Não usou & 10 & 0,454 & 45,4 \\
\hline \multicolumn{4}{|c|}{ Teste rápido para HIV na maternidade } \\
\hline Sim & 16 & 0,727 & 72,7 \\
\hline Não & 6 & 0,273 & 27,3 \\
\hline TOTAL & 22 & 1 & 100 \\
\hline
\end{tabular}

\section{c) Características Clínicas Obstétricas}

A Tabela 3 apresenta as colocações sobre a propedêutica interpartal pela demonstração da Idade Gestacional (IG) no momento do parto, do tempo de rotura de membranas e da via de parto.

Analisou-se a IG no momento do parto e foi constatado que $19(86,4 \%)$ parturientes tinham tempo de gestação igual ou maior que 38 semanas. A avaliação foi feita utilizando-se o parâmetro clínico obstétrico: data da última menstruação; quando não encontrada, estimou-se pela referência à ultrassonografia.
Quanto ao tempo de rotura das membranas, 12 $(54,5 \%)$ parturientes mantiveram suas bolsas íntegras, oito $(36,4 \%)$ apresentaram duração menor de quatro horas, e duas $(9,1 \%)$ aumentaram o risco da transmissão vertical por permanecerem com bolsa por tempo superior a quatro horas.

A operação cesariana foi a via de parto mais utilizada, sendo que $16(72,7 \%)$ gestantes receberam essa indicação sem utilizar a carga viral como determinante de escolha para a mesma, pois não foram encontradas informações sobre a carga viral nos prontuários hospitalares. 


\begin{tabular}{|c|c|c|c|}
\hline $\begin{array}{l}\text { TABELA 3: } \\
\text { com a idade } \\
\text { tempo de ro } \\
\text { Região do Ca }\end{array}$ & $\begin{array}{l}\text { n HI } \\
\text { do } \\
\text { dade }\end{array}$ & $\begin{array}{l}\text { ositivo } \\
\text { o, via d } \\
\text { le refer }\end{array}$ & $\begin{array}{l}\text { acordo } \\
\text { parto e } \\
\text { cias da }\end{array}$ \\
\hline Variáveis & $\mathbf{F}$ & Fr & $\%$ \\
\hline IG no momer & & & \\
\hline$=30<38$ & 3 & 0,136 & 13,6 \\
\hline$=38$ & 19 & 0,864 & 86,4 \\
\hline Tempo de rot & & & \\
\hline Bolsa íntegra & 12 & 0,545 & 54,5 \\
\hline$<$ que 4 horas & 8 & 0,364 & 36,4 \\
\hline$>$ que 4 horas & 2 & 0,091 & 9,1 \\
\hline Via de parto & & & \\
\hline Abdominal & 16 & 0,727 & 72,7 \\
\hline Vaginal & 6 & 0,273 & 27,3 \\
\hline TOTAL & 22 & 1 & 100 \\
\hline
\end{tabular}

Fonte: Pesquisa direta em prontuários hospitalares e fichas de notificação compulsória das gestantes HIV+ e crianças expostas. ${ }^{*}$ IG expressa em semanas.

d) Características da profilaxia e terapêutica ou Terapêutica da mãe e do recém-nascido

Analisou-se o manejo clínico das gestantes com HIV positivo instituído nas maternidades de referência, abrangendo desde o início da profilaxia perinatal comAZT intravenoso e a quantidade de horas de sua administração, atéa conduta empregada para inibição da lactação.

Na Tabela 4 observou-se que 17 (77,3\%) pacientes receberam AZT intraparto, entretanto cinco (22,7\%) não receberam. Dentreas pacientes quenão receberam AZT intraparto, duas chegaram em período expulsivo, não havendo tempo hábil para a administração do AZT. Em uma das pacientes, foi detectado óbito fetal, não sendo mais necessário dar continuidade ao Protocolo 076, e em dois casos o diagnóstico da infecção pelo HIV na paciente só aconteceu após o parto. Vale ressaltar que em todas essas mulheres que não fizeram uso do AZT houve evolução para parto vaginal, e em uma delas foi realizada episiotomia. Ainda, pode-se constatar que o parto cesáreo foi a via com total associação ao AZT intraparto.

Nesse sentido, foi possível identificar que nove $(40,9 \%)$ parturientes iniciaram o AZT intravenoso antes de três horas de internação, no entanto, duas $(9,1 \%)$ só iniciaram o AZT após 24 horas de internação devido à espera de exames de HIV para confirmação de diagnóstico em um caso, e, em outro, o teste rápido só foi realizado após 27 horas de internação.

Assim, conforme pode ser observado na Tabela 4, a quantidade de horas deAZT predominantefoi de três horas, o que ocorreu em oito $(36,6 \%)$ casos, seguidadeumtempo superioratrêshoras, ocorrendoem seis (27,3\%) casos. Dessaforma, pode-se inferir quese possibilitou uma proteçãoamais para ofeto.

Todas as parturientes do presente estudo que fizeram AZT intraparto realizaram o esquema completo, fazendo a dose de ataque na primeira hora eem seguida a dose de manutenção nas duasúttimas horas, como recomenda o Ministério daSaúde.

Com relação ao risco de transmissão vertical pelo aleitamento materno, foram realizados os seguintes métodos para a supressão da lactação: sete $(31,8 \%$ ) puérperas realizaram inibição mecânica, duas $(9,1 \%)$ puérperas fizeram inibição hormonal, enquanto oito $(36,4 \%)$ realizaram a associação dos dois métodos de inibição da lactação.

\begin{tabular}{|c|c|c|c|}
\hline \multicolumn{4}{|c|}{$\begin{array}{l}\text { TABELA 4: Manejo clínico na maternidade segundo } \mathbf{n}^{0} \text { de gestantes que fizeram } \\
\text { AZT intraparto, tempo: internação } \times \text { início de AZT, quantidade de horas de } \\
\text { AZT, método de inibição da lactação. Maternidades de referências da Região do } \\
\text { Cariri. Brasil. } 2003 \text { - } 2007 \text {. }\end{array}$} \\
\hline Variáveis & $\mathbf{F}$ & Fr & $\%$ \\
\hline \multicolumn{4}{|c|}{$\mathrm{N}^{\circ}$ de gestantes que fizeram AZT intraparto } \\
\hline Sim & 17 & 0,773 & 77,3 \\
\hline Não & 5 & 0,227 & 22,7 \\
\hline \multicolumn{4}{|c|}{ Tempo: internação $\times$ início de AZT } \\
\hline $0-3$ & 9 & 0,409 & 40,9 \\
\hline $3-6$ & 4 & 0,182 & 18,2 \\
\hline $7-10$ & 2 & 0,091 & 9,1 \\
\hline$>24$ & 2 & 0,091 & 9,1 \\
\hline Não se aplica & 5 & 0,227 & 22,7 \\
\hline \multicolumn{4}{|c|}{ Quantidade de horas de AZT } \\
\hline$<3$ horas & 3 & 0,136 & 13,6 \\
\hline 3 horas & 8 & 0,364 & 36,4 \\
\hline$>3$ horas & 6 & 0,273 & 27,3 \\
\hline Não se aplica & 5 & 0,227 & 22,7 \\
\hline \multicolumn{4}{|c|}{ Método de inibição da lactação } \\
\hline Mecânico & 7 & 0,318 & 31,8 \\
\hline Hormonal & 2 & 0,091 & 9,1 \\
\hline Mecânico+ Hormonal & 8 & 0,364 & 36,4 \\
\hline Sem informação do método & 4 & 0,182 & 18,2 \\
\hline Não realizou inibição & 1 & 0,045 & 4,5 \\
\hline TOTAL & 22 & 1 & 100 \\
\hline
\end{tabular}

Fonte: Pesquisa direta em prontuários hospitalares. 
Dando continuidade às atividades de análise, julgouse importante apresentar as variáveis relacionadas aos recém-nascidos (RNs) expostos ao HIV, tais como: uso de AZT solução oral; uso de fórmula infantil e o tempo entre o nascimento e o início do AZT xarope, a fim de explanar o manejo dos RNs nas maternidades no que diz respeito à profilaxia da transmissão vertical e uso AZT e relacionar com o que preconiza o Ministério da Saúde. Salienta-se que foi preferível explanar esses aspectos através da elaboração de um quadro.

QUADR0: Tratamento instituído para os recém-nascidos verticalmente expostos nas maternidades de referência. Região do Cariri. Brasil. 2003-2007

\begin{tabular}{|c|c|c|c|}
\hline $\begin{array}{l}\text { Recém- } \\
\text { nascidos }\end{array}$ & $\begin{array}{l}\text { Uso de AZT } \\
\text { solução oral } \\
\text { (xarope) }\end{array}$ & $\begin{array}{l}\text { Uso de fórmula } \\
\text { infantil (leite } \\
\text { artificial) }\end{array}$ & $\begin{array}{l}\text { Tempo: nascimento X início do AZT } \\
\text { xarope }\end{array}$ \\
\hline RN1 & Sim & Sim & nas primeiras 24horas \\
\hline RN2 & Sim & Sim & nas primeiras 24horas \\
\hline RN3 & Sim & Sim & nas primeiras 24horas \\
\hline RN4 & Sim & Sim & nas primeiras 24horas \\
\hline RN5 & Sim & Sim & nas primeiras 24horas \\
\hline RN6 & Sim & Sim & nas primeiras 24horas \\
\hline RN7 & Sim & Sim & nas primeiras 24horas \\
\hline RN8 & Sim & Sim & nas primeiras 24horas \\
\hline RN9 & Sim & Sim & nas primeiras 24horas \\
\hline RN10 & Sim & Sim & nas primeiras 24horas \\
\hline$\overline{\mathrm{RN} 11}$ & Sim & Sim & nas primeiras 24horas \\
\hline$\overline{\mathrm{RN} 12}$ & Sim & Sim & nas primeiras 24horas \\
\hline$\overline{\mathrm{RN} 13}$ & Sim & Sim & nas primeiras 24horas \\
\hline RN14 & Não se aplica & Não se aplica & Não se aplica \\
\hline$\overline{\mathrm{RN} 15}$ & Sim & Sim & nas primeiras 24horas \\
\hline RN16 & Sim & Sim & nas primeiras 24horas \\
\hline RN17 & Sim & Sem registro & após 24horas \\
\hline RN18 & Sim & Sim & nas primeiras 24horas \\
\hline RN19 & Sim & Sim & nas primeiras 24horas \\
\hline RN20 & Sim & Sim & nas primeiras 24horas \\
\hline RN21 & Sim & Sim & nas primeiras 24horas \\
\hline RN22 & Sim & Sim & nas primeiras 24horas \\
\hline
\end{tabular}

A avaliação dos dados desse quadro mostra que os cuidados direcionados aos RNs seguiram o que preconiza o MS, pois todos eles receberam terapia antirretroviral por solução oral, sendo que $20(91 \%)$ RNs o fizeram nas primeiras 24 horas de vida, enquanto apenas um RN só recebeu após as 24 horas, devido ao diagnóstico da infecção pelo HIV materna ter ocorrido após 33 horas do parto normal com episiotomia. 0 caso que não se aplica diz respeito ao feto morto.

Em relação ao uso de fórmula infantil, 20 (91\%) RNs o fizeram, não constando o registro em um $\mathrm{RN}$, o qual recebeu leite materno, tendo sida prescrita a amamentação e, logo depois, sido suspensa; supõe-se que tenha havido amamentação, pois a mãe desse RN, além do diagnóstico tardio, como já foi citado antes, também não utilizou nenhum tipo de inibição da lactação. Por outro lado, esse RN pode não ter sido amamentado por ter apresentado complicações: aspiração de mecônio, cianose, sofrimento respiratório, necessidade de incubadora aquecida e oxigênio sob halo, e com onze horas de vida foi prescrita dieta zero, sonda orogástrica aberta e venóclise.

A notificação compulsória das gestantes com HIV positivo e crianças expostas ocorreu nas maternidades de forma satisfatória, das 22 gestantes soropositivas para o HIV foram encontrados registros de 21 (95,45\%) fichas de notificação arquivadas.

Ao contrário disso, no Serviço de Vigilância Epidemiológica dos municípios só foram encontradas sete $(31,82 \%)$ fichas que alimentaram o Sistema de Informação de Agravos de Notificação-SINAN. Os casos em que foram encontrados registros nas maternidades e não estavam no SINAN foram informados aos Serviços de Vigilância Epidemiológica a fim de se realizar busca ativa e contribuir para a completitude da notificação dos casos. 


\section{DISCUSSÃO}

Neste estudo, identificou-se que a maioria das gestantes são jovens adultas, com pouca escolaridade, solteiras e do lar. Todas realizaram pré-natal, prevalecendo entre quatro a seis consultas, porém nem todas tiveram a oportunidade de realizar a profilaxia na gestação, identificando-se, portanto, um acompanhamento insatisfatório.

Sobre a avaliação das ações de controle de parto e nascimento dos RNs, em maternidades de Fortaleza-CE, encontraram-se características semelhantes; a maioria das parturientes com HIV tinha entre 22 e 29 anos, era solteira, com união estável, com pouco estudo, tinha entre um a dois filhos, conhecia o diagnóstico a menos de um ano e tinha seis ou mais consultas no pré-natal, e todas no trabalho parto realizaram tratamento antirretroviral, juntamente com seus RNs. ${ }^{8}$

A recomendação clássica na obstetrícia preconiza que toda gestante deverá comparecer mensalmente ao prénatal, quinzenalmente do sétimo ao nono mês, e semanalmente no último mês até o parto. ${ }^{9}$ No caso das gestantes com HIV, é necessário cumprir esse parâmetro ou exigir mais consultas, com intuito de melhor aconselhamento, realização do teste anti-HIV e efetiva utilização da Terapia Antirretroviral - TARV. ${ }^{10}$

As variáveis momento do diagnóstico e início do uso de antirretroviral são extremamente importantes, pois se constata como boa cobertura e captação precoce das gestantes para 0 pré-natal de qualidade institui em tempo hábil medidas de prevenção para a transmissão vertical. ${ }^{11}$

Desta feita, um estudo realizado no município de Fortaleza, Ceará, o qual buscou avaliar a adesão de gestantes com HIV positivo às condutas profiláticas de transmissão vertical do HIV, identificou que a prevalência do diagnóstico ocorreu durante o pré-natal e, ainda, que a grande maioria das gestantes recebeu o tratamento com AZT ainda na assistência pré-natalina, ${ }^{12}$ fato que não foi confirmado no presente estudo.

Esse estudo pode explanar que o diagnóstico durante, ou antes, do pré-natal constitui um fator primordial para a prevenção da transmissão vertical. Assim, a profilaxia na gestação esteve associada ao momento do diagnóstico, pois, das quinze que sabiam ser soropositivas antes ou durante a gestação, doze iniciaram a profilaxia a partir da $14^{\mathrm{a}}$ semana, como preconiza a literatura. Importante destacar quanto a esse dado o resultado de uma pesquisa que identificou os significados das gestantes sobre a realização do teste anti-HIV no pré-natal, dentre eles a possibilidade de prevenir a transmissão vertical, ou seja, proteger o filho, e ser este recurso laboratorial parte da assistência pré-natal. ${ }^{13}$
0 teste rápido para o HIV aconteceu em 16 (72\%) casos, independentes de já terem feito a sorologia antes ou durante o pré-natal. Esses testes são instrumentos de grande utilidade para aplicação do Projeto Nascer nas Maternidades e, consequentemente, à redução da transmissão vertical do HIV no terceiro trimestre da gestação, pois o período maior de transmissão ocorre no período intraparto $(65 \%){ }^{3}$

Para garantir a profilaxia no periparto, foi detectada nesse estudo a utilização da operação cesariana, visto que não constavam registro nos prontuários sobre a monitorização imunológica (contagem de linfócitos TCD4) e virológica (avaliação de carga viral), e ainda constatar que o parto cesáreo foi a via com total associação ao AZT intraparto.

Segundo o Ministério da Saúde, recomenda-se a cesariana eletiva com 38 semanas completas em todas as mulheres com carga viral superior a 1.000 cópias $/ \mathrm{mL}$, determinada a partir de 34 semanas, ou naquelas em que este parâmetro laboratorial não estiver disponível. Para mulheres com cargas virais inferiores à descrita ou indetectável, a via de parto deverá ser baseada na indicação obstétrica. ${ }^{14}$

Contudo, questionam-se atualmente os benefícios da cesariana quanto à carga viral materna, tendo em vista que o risco de transmissão é inferior a $2 \%$ para as mulheres com esquema tríplice de antirretrovial durante o pré-natal, e segue-se o protocolo 076 que mostra que a administração de AZT (endovenosos) na parturiente e no recém-nascido (solução oral) reduz a taxa de transmissão maternoinfantil. ${ }^{15}$.

0 esquema completo de AZT intrapar to foi administrado na maioria da população estudada, antes de três horas de internação e duração de AZT predominante de três horas $(36,6 \%)$. Pode-se inferir que as maternidades da Região do Cariri estão fazendo o possível para seguir as orientaç̃oes do Ministério da Saúde, e que se possibilitou uma proteção a mais para o feto. Constatou-se que em todas as mulheres que não fizeram uso do AZT houve evolução para parto vaginal e em uma dela foi realizada episiotomia.

Um estudo sobre dez anos de assistência obstétrica a portadores do HIV na maternidade das clínicas da Universidade Federal de Minas Gerais (UFMG) detectou valores menores, em que $8,8 \%$ das parturientes não receberam o medicamento endovenoso; a falha na administração de AZT intraparto esteve atrelada ao período expulsivo. ${ }^{15}$

Orientações durante o pré-natal sobre a identificação dos primeiros sinais/sintomas do início do trabalho de parto e a procura do atendimento hospitalar constitui um importante fator que possibilita a essas gestantes receberem o esquema completo de AZT no intraparto. ${ }^{16}$ Assim, o início da administração de AZT injetável está recomendado três horas do parto e mantido até a ligadura do cordão umbilical. ${ }^{5}$ 
Identificou-se que, no puerpério, os parâmetros recomendados para a prevenção de transmissão vertical do HIV pela inibição da lactação mecânica ou hormonal, ou pela associação dos dois métodos foram seguidos. Assim, é possível inferir que as orientações sobre este aspecto estão em concordância com a descrita na literatura, a qual recomenda o enfaixamento das mamas (inibição mecânica) por um período de dez dias, evitando-se a manipulação e estimulação, medida essa que, isolada, alcança sucesso em $80 \%$ dos casos. ${ }^{17}$

Utiliza-se a inibição hormonal quando há dificuldades na manutenção do enfaixamento durante o período prolongado no puerpério, permitindo que o seguimento do conjunto de medidas preconizadas resulte em importante redução da transmissão vertical. Outra medida recomendada é a remoção imediata de sangue e secreções em contato com pele e mucosa do RN. ${ }^{18}$

Quanto aos cuidados com os RNs, os seguimentos estão de acordo com o que está preconizado, pois todos receberam AZT solução oral - fórmula infantil; 20 (91\%) RNs o fizeram nas primeiras 24 horas de vida. Assim, os dados confirmam a possibilidade do tratamento da criança exposta em tempo hábil e melhor orientação da mãe quanto à suspensão da amamentação, adquirida durante o pré-natal ou parto.

No que diz respeito à notificação compulsória das gestantes com HIV positivo e crianças expostas, esta ocorreu nas maternidades de forma satisfatória; das 22 gestantes soropositivas para o HIV, foi encontrado registro 21 (95,45\%)fichas de notificação arquivadas no Núcleo Hospitalar de Epidemiologia- NUHEP, em desacordo com apenas sete $(31,82 \%)$ fichas que alimentaram o Sistema de Informação de Agravos de Notificação - SINAN.

Essa problemática traz consigo a mudança na real situação epidemiológica dos municípios, dificultando as produções científicas, pois muitos dos resultados encontrados nesse estudo não existiriam e, consequentemente, se perderia uma oportunidade de ampliação e solicitação desse conhecimento da realidade sobre o manejo das gestantes com HIV positivo na Região do Cariri.

\section{CONCLUSÕES}

0 estudo visou identificar a maneira como as gestantes com HIV positivo estão sendo acompanhadas, sobretudo, em se tratando do manejo clínico e medicamentoso, nas maternidades de referência da Região do Cariri após a implantação do Projeto Nascer.De modo geral, as maternidades investigadas seguem as orientações do MS quanto à assistência ao parto das gestantes com HIV positivo, no que diz respeito ao uso de teste rápido, escolha do tipo de parto, habilidade para iniciar a profilaxia com AZT intravenoso e tempo preconizado, inibição da lactação com métodos adequados e cuidados imediatos aos RNs.
De acordo com os resultados encontrados nessa pesquisa, as maternidades estudadas estão buscando dar assistência de qualidade às gestantes com HIV positivo durante o parto e puerpério, reduzindo os riscos da transmissão vertical, mediante o seguimento das consultas profiláticas recomendadas pelo MS.

Esses resultados possibilitam ampliar 0 conhecimento quanto à compreensão e organização da assistência às gestantes soropositivas, abrindo portas para novos questionamentos que dão margem à realização de novas pesquisas que possam incluir os profissionais da assistência primária, os gestores, a vigilância epidemiológica, os serviços de saúde, as mulheres infectadas pelo HIV e as crianças expostas

\section{REFERÊNCIAS}

1. Ministério da Saúde (BR). Guia de vigilância epidemiológica. $6^{\text {a ed. }}$ Brasília (DF); 2005.

2. Ministério da Saúde (BR). Secretária de Vigilância em Saúde. Programa Nacional de DST/AIDS. Bol Epidemiol AIDS /DST 2006; 3(1).

3. Ministério da Saúde (BR). Secretária de vigilância em Saúde. Programa nacional de DST/AIDS. Plano integrado de enfrentamento da feminização da epidemia de AIDS e outras DST. Brasília (DF); 2007a.

4. Ministério da Saúde (BR). Projeto nascer. Brasília (DF); 2003. 5. Ministério da Saúde (BR). Secretária de Vigilância em Saúde. Programa Nacional de DST /AIDS. Protocolo para prevenção de transmissão vertical de HIV e sífilis - manual de bolso. Brasília (DF); 2007b.

6. Ministério da Saúde (BR). Programa Nacional de DST e AIDS. Recomendações para profilaxia da transmissão vertical do HIV e terapia anti-retroviral em gestantes. Brasília (DF); 2006.

7. Associação Brasileira de Infectologia. Recursos disponíveis reduzem o risco da transmissão vertical. Infectologia. Hoje: Bol Atual Soc Bras Infectol 2006 out/nov/dez; 1(5). Disponível em: http://www.infectologia.org.br.

8. Barros LMM. Avaliação das ações de controle da transmissão vertical do HIV/AIDS entre puéperas atendidas em uma maternidade de FortalezaCE [dissertação de mestrado]. Fortaleza (CE): Universidade Federal do Ceará; 2005.

9. Freitas F, et al. Rotinas em obstetrícia. $5^{\text {a }}$ ed. Porto Alegre (RS): Artmed; 2006.

10. Rezende M. Doenças infecciosas. In: Obstetrícia fundamental. $10^{\mathrm{a}} \mathrm{ed}$. Rio de Janeiro (RJ): Guanabara Koogan; 2006. p.421-49.

11. Marques HHS, et al. Falhas na identificação da infecção pelo HIV durante a gravidez em São Paulo, 1998. Rev Saude Publica 2002; 36: 385-92. 
12. Cavalcante MS, et al. Prevenção da transmissão vertical do vírus da imunodeficiência humana: análise da adesão às medidas de profilaxia em uma maternidade de referência em Fortaleza, Ceará, Brasil. Rev Bras Saude Matern Infant 2008; 8 (4): 473-79.

13. Silva RMO, Araújo CLF, Paz FMT . A realização do teste anti-hiv no prénatal: os significados para a gestante. Esc Anna Nery Rev Enferm 2008 dez; 12(4): 630-36.

14. Ministério da Saúde. (BR). Recomendações para profilaxia da transmissão vertical do HIV e terapia antirretroviral em gestantes. Brasília (DF);2006 b.

15. Melo VH, et al. Resultados maternos e perinatais de dez anos de assistência obstétrica a portadoras do vírus da imunodeficiência humana. Rev Bras Ginecol Obstetr 2005 nov; 27 (11): 683-90.

16. Maturana AP, et al. Avaliação da assistência ao parto em gestantes infectadas pelo HIV. Arq Med ABC 2007; 32(1)11-6.

17. Ministério da Saúde (BR). HIV/AIDS, hepatites e outras DST. Brasilia (DF); 2006a. [Cadernos de Atenção Básica, 18]

18. Lindsey PC, Amed AM. Acompanhamento da Grávida HIV+. In: Camago L, et al. Guia de obstetrícia. Barueri (SP): Malone; 2005. p.593-99.

\section{NOTA}

aMonografia apresentada para conclusão de curso em Enfermagem da Universidade Regional do Cariri - URCA 